\title{
Beş Faktörlü Bilgece Farkındalık Ölçeği-Kısa Formu'nun (BFBFÖ-K) Türkçe Uyarlaması
}

\author{
Handan Deniz Ayalp ${ }^{1}$, Nesrin Hisli Şahin ${ }^{2}$
}

\author{
Anahtar kelimeler \\ bilgece farkındalık, \\ bilgece farkındalık \\ ölçeği, Türkçe uyarlama
}

\section{Key words}

mindfulness, mindfulness scale

Turkish adaptation

\begin{abstract}
Öz
Bilgece farkındalık konusu, son zamanlarda fiziksel ve psikolojik iyi oluş hali açısından büyük önem kazanmıştır. Bilgece farkındalık aynı zamanda bir kişilik özelliği ve bir müdahale tekniği olarak kavramsallaştırılmaktadır. Bilgece farkındalığı ölçmek üzere çeşitli ölçekler geliştirilmiştir. Bunlar arasında Toronto Bilgece Farkındalık Ölçeği (TBFÖ), Bilinçli Farkındalık Ölçeği (BİFÖ) ve Beş Boyutlu Bilinçli Farkındalık Ölçeği (BBBFÖ), Türkçeye uyarlanmış olanlardandır. Bu süreç içerisinde Beş Boyutlu Bilinçli Farkındalık Ölçeği’nin orijinal formu olan Five Facet Mindfulness Questionnaire (FFMQ) kısa form olarak geliştirilmiştir. Mevcut çalışmanın amacı, bu kısa formun Türkçeye uyarlanmasıdır. Araştırmada kullanılan diğer ölçme araçları; Demografik Bilgiler ve Kişisel Değerlendirmeler Formu, Toronto Bilgece Farkındalık Ölçeği (TBFÖ), Duygu Düzenleme Güçlüğü Ölçeği (DDGÖ) ve Kısa Semptom Envanteri (KSE)'dir. Araştırmanın örneklemi 18-75 yaş aralığındaki (Ort. $=25.59, S S=9.99) 268$ katılımcıdan $(165$ kadın, 99 erkek) oluşmuştur. Yapılan analizler sonucunda, ölçeğin kısa formunun Türkçe uyarlamasında da, orijinal formundaki beş faktörlü yapının korunduğu ve geçerlik ve güvenirlik gibi diğer psikometrik özelliklerinin uygun olduğu görülmüştür. Elde edilen verilerin 1şı̆̆ında, Beş Faktörlü Bilgece Farkındalık Ölçeği - Kısa Formu'nun (BFBFÖ-K) Türkiye'de ilgili alanyazına yönelik araştırmalarda kullanılabileceği düşünülmektedir.
\end{abstract}

\begin{abstract}
Turkish adaptation of the Five Facet Mindfulness Questionnaire - Short Form (FFMQ-S)

In recent years, mindfulness has been acknowledged as an important factor for physical and psychological well-being. At the same time, it is conceptualized as a personality characteristic as well as an intervention technique. Several assessment instruments were developed to measure mindfulness. Among these, Toronto Mindfulness Scale (TMS), Mindful Attention Awareness Scale (MAAS) and Five Facet Mindfulness Questionnaire (FFMQ) were adapted to Turkish language and culture. In the meantime, a short form of the Five Facet Mindfulness Questionnaire (FFMQ) was developed. The aim of the current study is to conduct a Turkish adaptation study for this short form. The other scales used in the study included Demographic Information and Personal Evaluation Questionnaire, Toronto Mindfulness Scale (TMS), Difficulties in Emotion Regulation Scale (DERS), and the Brief Symptom Inventory (BSI). The study sample consisted of 268 participants (165 women and 99 men), with an age range of 18-75 $(M=25.59, S D=9.99)$. The analyses revealed that the five-factor structure of the original form was preserved and other psychometric properties such as validity and reliability were found to be appropriate in the Turkish adaptation of the short form of the scale. In the light of the findings obtained, it is proposed that the Short Form of the Five Facet Mindfulness Questionnaire (FFMQ - Short Form) can be used with confidence in mindfulness-related research in Turkey.
\end{abstract}

Ayalp, H. D. ve Hisli Şahin, N. (2018). Beş Faktörlü Bilgece Farkındalık Ölçeği - Kısa Formu'nun (BFBFÖ-K) Türkçe Uyarlaması. Klinik Psikoloji Dergisi, 2(3), 117-127.

\footnotetext{
Handan Deniz Ayalp·hdenizayalp@gmail.com

${ }^{1}$ Psk., Başkent Üniversitesi, Fen Edebiyat Fakültesi, Psikoloji

Bölümü, Klinik Psikoloji Yüksek Lisans Programı, Ankara,

06810.

${ }^{2}$ Prof. Dr., New Jersey/Amerika Birleşik Devletleri

Not: Bu çalışma, ilk yazarın ikinci yazar danışmanlığında yaptığ lisans tezinin bir parçasıdır.
}

Geliş tarihi: 20.03.2018

Kabul tarihi: 07.09.2018 
Bilgece farkındalık, andaki mevcut olaylara ve deneyimlere karşı, özel bir tutum içinde yöneltilmiş dikkat ve farkındalıktır (Brown ve Ryan, 2003). Bilgece farkındalığın temelleri, 2500 y1l öncesinin Budist meditasyon egzersizlerine dayanmaktadır. Jon KabatZinn ve Langer, bu konudaki iki farklı yaklaşımın öncülerindendir. Langer, olguya tümüyle seküler bir algıyla yaklaşıp, bilgece farkındalı̆̆ diş çevrede, zihinde ve bedende olup bitenlere açık ama onlardan etkilenmeden anda yapılmakta olan iş üzerinde tutulabildiği bir beceri ve yaratıcılığ 1 kolaylaştırmaya yönelik bir zihinsel süreç olarak tanımlamaktadır (Langer, 1989; Levy ve Langer, 1999; Langer, 2000). Kabat-Zinn (1994) ise Budist geleneğe biraz daha yakın bir yaklaşımla, bilgece farkındalığ 1 dikkat yönetiminin ötesinde, zihinden geçenlere ve bedenden gelen sinyallere açıklık, kabulleniş, merak, anlayış ve şefkatle yaklaşımın gerçekleştiği, zihni ve bedeni dinginleştiren ve sağaltıma yardımcı bir tutum olarak tanımlamaktadır (akt. Hisli Şahin ve Yeniçeri, 2015). Yıllar içinde bilgece farkındalığın, zihinsel egzersizler sırasında oluşan anlık bir yaşantısal durum (state) ya da daha da yerleşik bir kişilik özelliği (trait) olarak ele alındığı ve ölçülmeye çalışıldığı görülmektedir. Örneğin, Kiken, Garland, Bluth, Palsson ve Gaylord (2015), tekrarlanan meditasyon oturumları sonucunda, anlık bilgece farkındalık deneyimi daha fazla artış gösteren katılımcıların, kişilik özelliği olarak da giderek daha bilgece farkındalıkla davrandıkları bir eğilim içine girdiklerini belirtmişlerdir.

Hem anlık bir yaşantı, hem de bir kişilik özelliği olarak bilgece farkındalığın, psikolojik ve fiziksel sağlıkla, beyin yapısındaki olumlu yöndeki değişimlerle, sağlıklı beslenme gibi olumlu davranışlarla ve ayrımcılığa maruz kalma gibi olumsuz davranışlar karşısında duygu yönetimiyle yakından ilişkili oldu$\breve{g u}$, çeşitli çalışmalarda gösterilmektedir (Brown, Weinstein ve Creswell, 2012; Brown-Ianuzzi, Adair, Payne, Richman ve Fredrickson, 2014; Jordan, Wang ve Donatoni, 2014; Lyvers, Makin, Toms, Thorberg ve Samios, 2014; Potts, 2015). Bilgece farkındalığın, beyindeki gri madde konsantrasyonundaki artışla (Hölzel ve ark., 2011; Murakami ve ark., 2012) ve geviş getirme (ruminasyon) tarzındaki düşüncelerin azalışıla (Young, 2007) ilişkili olduğunu gösteren çalışmalar da mevcuttur. Bugüne dek yapılmış pek çok araştırmada çoğunlukla pozitif psikolojik değişkenler ile ilişkili görülen bilgece farkındalık özelliklerinin, bağlanma stilleri (Bourne, Berry ve Jones, 2013; Pepping, O'Donovan ve Davis, 2014; Walsh, Balint, Smolira, Fredericksen ve Madsen, 2009) ve duygu düzenleme becerileri ile ilişkili olduğu da bulunmuştur (Davidson ve ark., 2003; Hill ve Updegraff, 2012; Hülsheger, Alberts, Feinholdt ve Lang, 2012; Jimenez, Niles ve Park, 2010; Karacaoğlan ve Hisli Şahin, 2016; Teper, Segal ve Inzlicht, 2013).
Bilgece farkındalığın anlık bir yaşantı oluşu özelliğine dayandırılarak oluşturulan çeşitli müdahale programları, kişilerin mevcut andaki deneyimlerine odaklanmalarını ve onlardan etkilenmememelerini kolaylaştıracak egzersizleri içermektedir. Bu egzersizler, insanları çektikleri acılardan özgürleştirmek üzerine tasarlanmışken, modern toplumda nükseden depresyonu önlemek üzere de başarılı bir biçimde uyarlanmış ve etkililikleri sınanmıştır (Cullen, 2011; Young, 2011). Bilgece farkındalık egzersizlerinin çeşitli hastalıklarda bir tedavi ve müdahale yöntemi olarak kullanıldığı çok sayıda çalışma mevcuttur. Bunlar arasında, sedef hastalığı hastalarıyla (KabatZinn ve ark., 1998); HIV hastalarıyla (Antoni ve ark., 2000); yeme bozukluklarından muzdarip hastalarla (Proulx, 2008); göğüs ve prostat kanseri hastalarıyla (Carlson, Speca, Faris ve Patel, 2007) yapılmış araştırmalar sayılabilir. Bilgece farkındalık egzersizlerinin bağışıklık sistemiyle (Davidson ve ark., 2003) ve beyin dalgalariyla (Lutz, Greischar, Rawlings, Ricard ve Davidson, 2004) olumlu yönde bir ilişki içinde olduğunun gösterildiği çeşitli çalışmalar da bulunmaktadır.

Bilgece farkındalık üzerinde çeşitli araştırmalar yapıldıkça, bu kavramın çeşitli bileşenlerden oluştuğu da gözlenmekte ve yeni araştırmalar bu boyutları da inceleme yönünde evrilmektedir. Söz konusu araştırmaların bir kısmı beyin görüntüleme tekniklerini kullanırken, diğer bir kısmı da klasik öz-bildirim ölçeklerini kullanmaktadır. Örneğin, Frewen ve arkadaşları (2010) tarafindan yapılan bir çalışmanın bulgularına göre, bir bilgece farkındalık bileşeni olan "gözlemleme"nin, dorsomedial prefrontal korteks ve sol amigdala aktivasyonunu yordadığı; bir diğer bilgece farkındalık bileşeni olan "farkındalıkla hareket etme"nin ise yalnızca dorsomedial prefrontal korteks aktivasyonunu yordadığı sonucuna varılmıştır. Paul, Stanton, Greeson, Smoski ve Wang (2013) ise, yaptıkları bir çalışmada yine bir bilgece farkındalık bileşeni olan "tepkisel olmama" özelliğinin, ruminasyon ve yaşanan stres sırasındaki negatif yanlılıklar ile negatif bir ilişki içerisinde olduğunu göstermiş ve buna ek olarak, bireyleri depresyonun psikolojik risklerine karşı koruduğunu belirtmişlerdir. Pirson, Langer, Bodner ve Zilcha-Mano'ya (2012) göre; bilgece farkındalığa yönelik ilginin son yıllarda böylesine artmış olması; bu değişkenin kavramsallaştırılmasına ve ölçülmesine yönelik pek çok girişimi de beraberinde getirmiş̧tir. Bilgece farkındalığ ölçmek üzere çalışmalar yapan araştırmacıların geliştirdikleri ölçekler, farklı türden yapılara sahiptir (Bergomi, Tschacher ve Kupper, 2013). Mevcut bilgece farkındalık ölçeklerinin bazıları tek faktörlü yapıya sahipken, bazı ölçeklerde faktör sayısı 5'e kadar yükselmektedir. Bu ölçekler arasında, 39 maddelik Kentucky Inventory of Mindfulness Skills (KIMS) (Baer ve ark., 2004; Bergomi ve ark., 2013); 30 maddelik 
Freiburg Mindfulness Inventory (FMI) (Walach, Buchheld, Buttenmüller, Kleinknecht ve Schmidt, 2006); 14 maddelik Freiburg Mindfulness Inventory Short Form (FMI - Short Form) (Walach ve ark., 2006); 12 maddelik Cognitive and Affective Mindfulness Scale - Revised (CAMS-R) (Feldman, Hayes, Kumar, Greeson ve Laurenceau, 2007); 16 maddelik Southampton Mindfulness Questionnaire (SMQ) (Chadwick ve ark., 2008) ve 20 maddelik Philadelphia Mindfulness Scale (PHLMS) (Cardaciotto, Herbert, Forman, Moitra ve Farrow, 2008) yer almaktadır. Bilgece farkındalık ölçekleri arasından Türkçeye uyarlanmış olanlar ise; Brown ve Ryan tarafından 2003 yılında yayınlanmış olan (Brown ve Ryan, 2003) ve Türkçeye 2011 yılında Özyeşil, Arslan, Kesici ve Deniz (2011) tarafından uyarlanan Bilinçli Farkındalık Ölçeği (BİFÖ) (Mindful Attention Awareness Scale-MAAS); Baer, Smith, Hopkins, Krietemeyer ve Toney tarafindan 2006 yilında, Kentucky Inventory of Mindfulness Skills'in (KIMS)'in revize edilerek oluşturulan (Bergomi ve ark., 2013) ve dilimize 2013 yılında Kınay (2013) tarafından Beş Boyutlu Bilinçli Farkındalık Ölçeği (BBBFÖ) olarak çevrilen 39 maddelik, Five Facet Mindfulness Questionnaire (FFMQ); Lau ve ark. tarafindan 2006 yilında geliştirilen ve 13 maddeden oluşan, Türkçe'ye Hisli Şahin ve Yeniçeri tarafindan 2015 yılında Toronto Bilgece Farkındalık Ölçeği (TBFÖ) adıyla kazandirılan, Toronto Mindfulness Scale (TMS) olarak sayılabilir.

Buraya kadar görüldüğü gibi; yurt dışında bilgece farkındalığı ölçmek üzere çok sayıda ölçek geliştirilmişken, bunlardan ancak 3 tanesi Türkçe'ye uyarlanmıştır. Ancak ilgili yazında hem anlık bir durum hem de bir kişilik özelliği olan bilgece farkındalığın, hızla yaygınlaşan bir şekilde, pek çok araştırmada yer aldığ 1 görülmektedir. Hâlihazırda kullanılmakta olan bilgece farkındalık ölçekleri (Toronto Bilgece Farkındalık Ölçeği ve Bilinçli Farkındalık Ölçeği) faktör yapıları ve madde sayıları gereği Beş Faktörlü Bilgece Farkındalık Ölçeği - Kısa Formu'na (BFBFÖ-K) (Tran, Glück ve Nader, 2013) kıyasla daha kısıtlıdır. Söz konusu ölçeklerde madde sayıları 13 ve 15 arasında değişirken, sırasıyla 2 faktörlü ve tek faktörlü yapıya sahip oldukları görülmektedir. BFBFÖ-K ise, madde sayısı olarak diğerleri gibi k1sa sayılabilecek (20 madde) bir ölçek iken, 5 faktörlü yapısıyla bilgece farkındalık kavramının içerdiği ileri sürülen çeşitli boyutları daha iyi yansıtabileceği düşünülmektedir. Bu nedenle mevcut çalışmanın amacı, Türkçe bilgece farkındalık ölçeklerine hem kısa hem de çok boyutlu yeni bir ölçek kazandırmaktır. Ölçeğin uyarlanabilmesiyle ilişkili gerekli izin, ölçeği 2013 y1lında geliştirmiş olan Tran, Glück ve Nader'den alınmıştır. Çalışmanın sonucunda BFBFÖ-K'nin toplam ölçek ve alt ölçekleriyle birlikte, araştırmada kriter ölçümleri olarak kullanılan diğer bilgece farkındalık ölçeği olan
Toronto Bilgece Farkındalık Ölçeği (TBFÖ) ile pozitif yönde, psikolojik sorun göstergeleri olarak değerlendirilebilecek Kisa Semptom Envanteri (KSE) ve Duygu Düzenleme Güçlüğü Ölçeği (DDGÖ) ile de negatif yönde ilişki içinde olması beklenmektedir. Araştırmada kullanılacak Demografik Bilgiler ve Kişisel Değerlendirmeler Formu'nda, katılımcılara konu bağlamında sorulacak olan ve kişinin kendisini, hayatını ve aile ilişkilerini değerlendirmesine yönelik bazı sorulardan elde edilmesi planlanan bazı indeks ölçümleriyle de pozitif yönde ilişkiler çıkması beklenmektedir.

\section{YÖNTEM}

\section{Örneklem}

$\mathrm{Bu}$ çalışmanın örneklemi, 18-75 yaş aralığındaki çeşitli yaş gruplarından 268 katılımcıdan oluşmaktadır (\% 61,6 kadın, \%36,9 erkek). Örneklemin büyük çoğunluğu $(\% 73,5), 18-25$ yaş aralığındadır. Katılımcıların \%94,3'ü $(\mathrm{N}=253)$ ekonomik düzeylerini orta $(\% 50,7)$, iyi $(\% 38,4)$ ve çok iyi $(\% 5,2)$ olarak değerlendirmişlerdir. Yaşam doyumlarını orta $(\% 36,3)$, yüksek $(\% 44,6)$ ve çok yüksek $(\% 7,5)$ olarak değerlendiren katılımciların toplam yüzdesinin, \%88,1 $(\mathrm{N}=236)$ olduğu görülmüştür.

\section{Veri Toplama Araçları}

Demografik Bilgiler ve Kişisel Değerlendirmeler Formu Bu formda, katılımciların birtakım demografik bilgileri ve bazı psikolojik değişkenlerle ilişkili olabilecek kişisel değerlendirmelerine ulaşabilmek hedeflenmiştir. Söz konusu psikolojik değişkenler kişinin hâlihazırdaki hayatını, kendisini, ilişkilerini nasıl değerlendirdiğiyle ilişkilidir ve bunların da objektif ölçeklerle ölçülmeye çalışılan değişkenleri destekleyici subjektif bilgiler verebileceği düşünülmüştür. Bunlar arasında sayılabilecekler şunlardır: (1) medeni hal, (2) hayat ve gelecek, (3) yakın ilişkiler, (4) fiziksel ve psikolojik sağlik, (5) kendilik değeri, (6) kişisel başarılar, (7) içinde büyüdüğü birincil aile, (8) birincil aile ve çevre desteği, (9) yalnızlık düzeyi, (10) duygu düzenleme becerisi ve (11) tepkilerini erteleyebilme becerisi. Bu değişkenlerden 3., 4., 5., 6., 8. ve 9.'nun toplamı ile Kendilik Değerlendirmesi; 2. ile Hayat Değerlendirmesi ve 7. ile 8.'nin toplamı ile de Aile İlişkileri Değerlendirilmesi indeks puanları oluşturulmuştur. Söz konusu bu değerlendirmelerin, ilgili yazın bağlamında çalışma açısından önem arz edeceği düşünülmüştür.

Beş Faktörlü Bilgece Farkındalık Ölçeği - Kısa Formu (BFBFÖ-K) Bu ölçek orijinal olarak 2006 yılında Baer ve arkadaşları tarafından 39 madde olarak geliştirilmiş olan Five Facet Mindfulness 
Questionnaire (FFMQ) ölçeğinin kısaltılmış formudur. Tran ve arkadaşları tarafından 2013 yılında yapılan çalışmada; ölçeğin orijinal formundaki güvenilirlik ve geçerlik seviyeleri korunarak, FFMQ, 39 maddeden 20 maddeye indirgenmiştir. Çalışma sırasında FFMQ'dan indirgenmiş olan 20 maddenin 10 tanesi ters olarak ifade edildiği halde (FFMQ'nun 5., 8., 13., 14., 16., 18., 22., 25., 30. ve 35. maddeleri) araştırmacılar bu maddeleri düz hale getirilerek ölçeğe dahil etmişlerdir. Orijinal formu ile aynı olan her 5 faktör ("Gözlemleme", "Tanımlama", "Farkındalıkla Hareket Etme", "İçsel Deneyimi Yargılamama" ve "İçsel Deneyime Tepkisel Olmama") için elde edilen Cronbach Alfa değerleri, her bir alt ölçek için surasıyla $.78, .89, .80, .85$ ve .69 olarak bulunmuştur (Tran ve ark., 2013). Mevcut uyarlama çalışmasında, söz konusu 10 maddenin, 39 maddelik orijinal ölçekte bulunduğu gibi ters halde kullanılması tercih edilmiştir. Katılımcıların bilgece farkındalık düzeylerini ölçmek amacıyla geliștirilmiş olan bu ölçeğin Türkçe'ye çeviri çalışması; Başkent Üniversitesi Psikoloji Bölümü ile Başkent Üniversitesi Amerikan Kültürü ve Edebiyatı Bölümü'nden, alanında uzman kişiler tarafindan yapılmıştır. Ölçek, öncelikle 3 farklı öğretim elemanı tarafindan İngilizce'den Türkçe'ye çevrilmiş ve çeviriler karşılaştırılarak en uygun çeviri yeniden, bu kez 2 farklı öğretim elemanı tarafından Türkçe'den İngilizce'ye çevrilmiştir. Ortaya çıkan bu İngilizce çevirilerin birbirine çok benzediği görüldükten sonra, ölçeğin orijinal İngilizce hali ile kıyaslama yapılmış; orijinal form ile uyuştukları görülmüş ve Türkçe çevirinin kullanılabilirliğine karar verilmiştir. Ölçek maddelerinin değerlendirilmesi amacıyla, ölçeğin hem orijinal uzun formu, hem de kisa formunda olduğu gibi 5'li Likert Tipi değerlendirme (1=Hiçbir Zaman, 2=Nadiren, 3=Bazen, 4=S1klıkla, 5=Hemen Her Zaman) kullanılmıştır.

Duygu Düzenleme Güçlüğ̈̈ Ölçeği (DDGÖ) Yapılmış olan pek çok çalışmada belirtildiği üzere; bilgece farkındalık, duygu düzenleyebilme becerisi ile pozitif yönlü bir ilişki içerisindedir. Mevcut çalışmada katılımcıların bilgece farkındalık düzeylerinin ölçülmesinin yanı sıra, deneyimledikleri duygu düzenleme güçlüğünün de ölçülmesi amaciyla bu ölçek, veri toplama aracı olarak çalışmaya dahil edilmiştir. Orijinal ismi Difficulties in Emotion Regulation Scale (DERS) olan ölçek, Gratz ve Roemer (2004) tarafından geliştirilmiştir. Ölçek, 36 maddeden oluşmaktadır, 5'li Likert tipi yapıya sahiptir ve "Farkındalık Eksikliği", "Belirginlik Eksikliği”, "Kabullenmeme", "Dürtüsellik", "Amaçsızlık/Hedefsizlik" ve "Strateji Yoksunluğu" olmak üzere toplamda 6 alt ölçekten oluşarak; kişilerin duygu düzenlemede yaşadıkları güçlüğü ölçmeyi amaçlamaktadır. Ölçeğin Cronbach Alfa katsayısının .93 olduğu ve her bir alt ölçek için hesaplanan Cronbach Alfa değerinin .80'in üzerinde bulunduğu belirtilmiştir (Gratz ve Roemer, 2004). Ölçeğin Türkçe'ye uyarlanması, Duygu Düzenleme Güçlüğü Ölçeği (DDGÖ) adıyla, Rugancı ve Gençöz (2010) tarafından yapılmıştır. Ölçeğin yapı geçerliliğini incelemek için Kısa Semptom Envanteri (KSE) kullanılmış ve 2 ölçek arasında güçlü pozitif ilişki bulunmuştur $(r=.58, p<.001)$. Yapılan analizler sonucunda ölçeğin toplam Cronbach Alfa değerinin .93 olduğu görülürken; Belirginlik Eksikliği, Amaçsızlık/Hedefsizlik, Dürtüsellik, Kabullenmeme, Strateji Yoksunluğu ve Farkındalık Eksikliği alt ölçekleri için Cronbach Alfa katsayıları sirasıyla .82, $.90, .90, .83, .89$ ve .75 olarak belirtilmiştir (Ruganc1 ve Gençöz, 2010). Mevcut çalışmada ölçeğin toplam Cronbach Alfa değerinin .92 olduğu; Amaçsızlık/ Hedefsizlik, Strateji Yoksunluğu, Kabullenmeme, Dürtüsellik, Belirginlik Eksikliği ve Farkındalık Eksikliği alt ölçekleri için Cronbach Alfa değerlerinin sirasiyla $.79, .85, .84, .81, .75$ ve .65 olduğu sonucu elde edilmiştir.

Toronto Bilgece Farkındalık Ölçeği (TBFÖ) Lau ve arkadaşları tarafından 2006 yılında geliştirilen Toronto Bilgece Farkındalık Ölçeği (The Toronto Mindfulness Scale - Trait), 13 maddeyi kapsayan iki faktörlü bir yapıya sahiptir (Etkilenmeden İzleme ve Merak). Çalışmada ilk faktörün (Etkilenmeden İzleme) Cronbach Alfa katsayıs1 .91 ve ikinci faktörün (Merak) Cronbach Alfa katsayısı .85 olarak bulunurken; ölçeğin toplam Cronbach Alfa değerinin .95 olduğu rapor edilmiştir. Hisli Şahin ve Yeniçeri (2015) tarafindan Türkçe'ye uyarlanan ölçek, uyarlama sonucunda faktör yapısını ve madde sayısını korumuştur. Ölçeğin toplam Cronbach Alfa katsayıs1 .60, Etkilenmeden İzleme alt ölçeğinin Cronbach Alfa katsayısı .71 ve Merak alt ölçeğininki ise .41 olarak bulunmuştur (Hisli Şahin ve Yeniçeri, 2015). Karacaoğlan ve Hisli Şahin (2016) tarafından yapılan başka bir çalışmada, ölçeğin toplam Cronbach Alfa güvenilirlik katsayısının .87 olduğu belirtilirken; Merak alt ölçeği için Cronbach Alfa güvenilirlik katsayısının .83 ve Etkilenmeden İzleme alt ölçeği için ise Cronbach Alfa güvenilirlik katsayısının .78 olduğu rapor edilmiştir. Mevcut çalışmada ölçeğin toplam Cronbach Alfa değerinin .80 olduğu; Merak ve Etkilenmeden İzleme alt ölçeklerinin Cronbach Alfa değerlerinin ise sırasıyla .74 ve .65 olduğu sonucuna ulaşı1mıştır.

Kısa Semptom Envanteri (KSE) Orijinal ismi Brief Symptom Inventory (BSI) olan ölçek, 1992 yılında Derogatis tarafından geliştirilen ve 53 maddeyi içeren kendini tarama türü bir envanterdir. KSE, 90 maddelik Semptom Belirleme Listesi'nin (SCL-90) 5-10 dakika içerisinde doldurulmaya uygun, kısaltılmış bir formudur. Geçerlik ve güvenilirliği ile ilgili olarak Derogatis (1992) tarafindan 719 psikiyatrik hasta üzerinde yapılmış olan bir çalışmada dokuz alt ölçek 
Tablo 1. Faktör Analizine Göre Maddelerin Faktör Yükleri ve Faktörlere Dağılımları

\begin{tabular}{|c|c|c|c|c|c|}
\hline Ölçek Maddeleri & $\begin{array}{c}\text { Dikkati } \\
\text { Düzenleyebilme }\end{array}$ & $\begin{array}{l}\text { Yargilamadan } \\
\text { Gözleme ve } \\
\text { İzleme }\end{array}$ & $\begin{array}{l}\text { Etkilenmeden } \\
\text { Gözleme ve } \\
\text { İzleme }\end{array}$ & $\begin{array}{c}\text { Duyumsal } \\
\text { Farkındalık }\end{array}$ & $\begin{array}{c}\text { Duygularını } \\
\text { İsimlendirebilme }\end{array}$ \\
\hline Dikkat sürdürme güçlüğü (10) & .864 & .096 & .036 & -.038 & .148 \\
\hline Dikkat dağınıklı̆̆ı (12) & .828 & .129 & -.078 & .025 & .062 \\
\hline Dikkati odaklayamama (11) & .813 & .105 & .051 & -.008 & .114 \\
\hline Dikkatin dağılması (9) & .810 & .082 & -.059 & .064 & -.003 \\
\hline Düşünce yargılama (14) & .053 & .833 & .099 & .015 & .037 \\
\hline Düşünce etiketleme (15) & .080 & .787 & .065 & .095 & .134 \\
\hline Duyguları yargılama (13) & .190 & .779 & -.042 & .030 & .004 \\
\hline Duyguları etiketleme (16) & .070 & .640 & .002 & .042 & .050 \\
\hline Duyguları gözleme (18) & -.038 & .089 & .801 & .069 & .041 \\
\hline Farkında olabilme (19) & -.025 & .011 & .769 & .061 & .035 \\
\hline Etki altında kalmama (20) & -.057 & .097 & .655 & .057 & -.113 \\
\hline Tepki erteleyebilme (17) & .082 & -.078 & .652 & .088 & -.063 \\
\hline Görsel farkındalık (2) & -.134 & .016 & .081 & .767 & -.147 \\
\hline Duyum farkındalığg (1) & .072 & -.025 & .106 & .713 & .122 \\
\hline İşitsel farkındalık (4) & .121 & .173 & -.008 & .706 & .011 \\
\hline Koku farkındalığı (3) & -.019 & .038 & .131 & .648 & -.276 \\
\hline Yaşantı farkındalığı (8) & -.041 & .007 & .260 & .278 & -.700 \\
\hline İfade etme güçlüğü (5) & .326 & .150 & .164 & .116 & .691 \\
\hline Tanımlama güçlüğü (7) & .354 & .154 & .058 & .164 & .663 \\
\hline Duygu tanımlayabilme (6) & .166 & -.032 & .104 & .291 & -.652 \\
\hline
\end{tabular}

Not: Parantez içindeki sayılar madde numaralarını göstermektedir. .64'ün üzerindeki faktör yükleri tabloda kalın yazı tipiyle gösterilmiştir.

için iç tutarlılık katsayılarının, .71 (psikotisizm) ile .85 (depresyon) arasında değiștiği belirtilmektedir (akt. Hisli Şahin, Durak Batıgün ve Uğurtaş, 2002). Ölçek, Hisli Şahin ve arkadaşları (2002) tarafından Türkçe'ye uyarlanmıştır. Kısa Semptom Envanteri'nin ergenlerde kullanımı için yapılan bu uyarlama çalışmasında, alt ölçeklerden elde edilen iç tutarlılık değerlerinin .70 (somatizasyon) ile .88 (depresyon) arasında değiștiği ve ölçeğin toplam iç tutarlılık değerinin .94 olduğu belirtilmiştir. Uyarlama çalışması sonucunda, ölçeğin orijinal formundan farklı olarak 5 faktörlü bir yapı (Anksiyete, Depresyon, Olumsuz Benlik, Somatizasyon ve Hostilite) elde edilmiştir (Hisli Şahin ve ark., 2002). Mevcut çalışmada ölçeğin toplam Cronbach Alfa değerinin .97 olduğu; Anksiyete, Depresyon, Olumsuz Benlik, Somatizasyon ve Hostilite alt ölçeklerinin Cronbach Alfa değerlerinin ise sirasiyla $.91, .92, .89, .85$ ve .75 olduğu sonucu elde edilmiştir.

\section{İşlem}

Çalışmaya katılmak konusunda katılımcıların gönüllülüğü esas alınmıştır. Katılımcılara, araştırmacılar ve araştırmanın amacı ile ilgili bilgi verilerek sözlü onamları alındıktan sonra, ölçek ile ilgili genel bir açıklama yapılmış ve bilgilendirilmiş onam formu ile başlayan ölçek bataryası uygulanmaya başlanmıştır. Ölçek bataryasının tamamlanarak teslim edilmesi, yaklaşık olarak 20-25 dakika sürmüştür.

\section{BULGULAR}

Araştırma başlangıcında, 300 kişilik bir örneklem ile çalışılması hedeflenmiştir. Ancak araştırma süreci boyunca 23 katılımcıdan elde edilen verilere ulaşılamamıştır. 9 katılımcıdan elde edilen verilerin de analiz için uygun olmadığ düşünülerek, bu veriler değerlendirme dışı bırakılmışıtır. Tüm bunların sonucunda; toplamda 268 kat1lımcidan elde edilen verilere uygulanan faktör, güvenilirlik ve korelasyon analizleri, SPSS 20.0 programında yapılmıştır.

\section{Beş Faktörlü Bilgece Farkındalık Ölçeği - Kısa Formu'nun (BFBFÖ-K) Psikometrik Özellikleri Faktör Analizi}

Ölçeğin Türkçe uyarlamasının, (1) orijinal formunun psikometrik özelliklerine yakın olup olmadığının değerlendirilmesi ve (2) genel olarak psikometrik özelliklerinin incelenmesi amaciyla toplamda 268 katılımcidan elde edilen verilere SPSS 20.0 programında açımlayıcı faktör analizi (temel bileşenler analizi) uygulanmıştır. Yapılan analiz sonucunda, 
Tablo 2. Beş Faktörlü Bilgece Farkındalık Ölçeği - Kısa Formu (BFBFÖ-K), Alt Ölçekleri ve Diğer Bazı Değişkenlerin Ortalama ve Standart Sapma Değerleri ile Değişkenler Arası Korelasyonlar

\begin{tabular}{|c|c|c|c|c|c|c|c|c|c|c|c|}
\hline Değişkenler & Ort. & S.S. & 1 & 2 & 3 & 4 & 5 & 6 & 7 & 8 & 9 \\
\hline $\begin{array}{l}\text { 1.Dikkati } \\
\text { Düzenleyebilme }\end{array}$ & 12,20 & 3,88 & - & $.269 * *$ & .003 & -.028 & $.285^{* *}$ & $.637 * *$ & $-.429 * *$ & $-.477 * *$ & .062 \\
\hline $\begin{array}{l}\text { 2.Yargilamadan } \\
\text { Gözleme ve İzleme }\end{array}$ & 12,21 & 3,45 & & - & -.087 & $-.129 *$ & $.169 * *$ & $.492 * *$ & $-.304 * *$ & $-.300 * *$ & -.090 \\
\hline $\begin{array}{l}\text { 3.Etkilenmeden } \\
\text { Gözleme ve İzleme }\end{array}$ & 12,72 & 3,22 & & & - & $.207 * *$ & .072 & $.436 * *$ & $-.172 * *$ & $-.288 * *$ & $.233 * *$ \\
\hline $\begin{array}{l}\text { 4. Duyumsal } \\
\text { Farkındalık }\end{array}$ & 13,78 & 3,22 & & & & - & $.140 *$ & $.428 * *$ & -.016 & -.084 & $.243 * *$ \\
\hline $\begin{array}{l}\text { 5.Duygularını } \\
\text { İsimlendirebilme }\end{array}$ & 14,38 & 2,94 & & & & & - & $.608 * *$ & $-.209 * *$ & $-.374 * *$ & $.173 * *$ \\
\hline $\begin{array}{l}\text { 6.BFBFÖ-K } \\
\text { Toplam Puan }\end{array}$ & 65,29 & 8,73 & & & & & & - & $-.450 * *$ & $-.593 * *$ & $.225^{* *}$ \\
\hline $\begin{array}{l}\text { 7.KSE Toplam } \\
\text { Puan }\end{array}$ & 114,9 & 39,99 & & & & & & & - & $.599 * *$ & $-.144 *$ \\
\hline $\begin{array}{l}\text { 8.DDGÖ Toplam } \\
\text { Puan }\end{array}$ & 86,5 & 21,27 & & & & & & & & - & $-.176 * *$ \\
\hline $\begin{array}{l}\text { 9.TBFÖ Toplam } \\
\text { Puan }\end{array}$ & 44,9 & 7,45 & & & & & & & & & - \\
\hline
\end{tabular}

$* \mathrm{p}<.05, * * \mathrm{p}<.01$. Not. Ort. ve S.S. kısaltmaları, Ortalama ve Standart Sapma kelimelerini ifade etmektedir.

ölçeğin orijinal formundaki 20 maddelik ve 5 faktörlü yapının korunduğu, her faktörde 4'er maddenin bulunduğu ve ölçekte toplamda 10 tane ters madde bulunduğu sonucu elde edilmiştir.

Tablo 1'de görüldüğü gibi, Dikkati Düzenleyebil$m e$ ismindeki 1. faktörde bulunan maddelerin (9., 10., 11. ve 12. maddeler) madde yükleri .81 ile .86; Yargllamadan Gözleme ve İzleme ismindeki 2. faktörde bulunan maddelerin (13., 14., 15. ve 16. maddeler) madde yükleri .64 ile .83; Etkilenmeden Gözleme ve İleme ismindeki 3 . faktörde bulunan maddelerin (17., 18., 19. ve 20. maddeler) madde yükleri 65 ile .80; Duyumsal Farkındalık ismindeki 4. faktörde bulunan maddelerin (1., 2., 3. ve 4. maddeler) madde yükleri .65 ile .77 ve Duygularını Ísimlendirebilme ismindeki 5. faktörde bulunan maddelerin (5., 6., 7. ve 8 . maddeler) madde yükleri de -.70 ile .69 aralığında değişkenlik göstermektedir. Analiz sonucunda, ölçek maddelerinin beklenen faktörler altında toplanmış olduğu gözlenmiştir.

\section{Güvenilirlik Bulgulart}

"Kişinin anlık deneyimlerine katılımını ve konsantre olmasını" ifade eden Dikkati Düzenleyebilme alt ölçeğinin Cronbach Alfa değeri .85 olarak hesaplanmıştır. Alt ölçeğin sahip olduğu 4 maddenin tamamı, ters maddelerdir. "Düşünce ve duygulara karşı yarg1layıcı bir duruşa sahip olmamak" anlamına gelen Yargılamadan Gözleme ve İzleme alt ölçeğinin Cronbach Alfa değeri .76 olarak hesaplanmıştır. Alt ölçeğin sahip olduğu 4 maddenin tamamı, ters maddeler- dir. "Duygu ve düşüncelere kapılmadan; sadece gelip gitmelerine izin verme eğilimine sahip olma" anlamını karşılayan Etkilenmeden Gözleme ve İzleme alt ölçeğinin Cronbach Alfa değeri .71 olarak hesaplanmıştır. "Kişinin duyumlar, bilişler, duygular gibi içsel ve dışsal deneyimlerini fark etmesi" anlamını karş1layan Duyumsal Farkındalık alt ölçeğinin iç tutarlılık değerini belirten Cronbach Alfa değeri .69 olarak hesaplanmıştır. Beşinci ve son alt ölçek olan; "içsel deneyimleri kelimelerle tanımlayabilme" anlamına gelen Duygularını İsimlendirebilme alt ölçeğinin Cronbach Alfa değeri ise .69 olarak hesaplanmıştır. Alt ölçeğin sahip olduğu 4 maddeden 2 tanesi, ters maddelerdir. BFBFÖ-K'nin toplam iç tutarlılığını ifade eden Cronbach Alfa değerinin ise .71 olduğu sonucuna ulaşılmıştır.

\section{Kriter Geçerliği Bulguları}

Mevcut ölçeğin tamamı, alt ölçekleri, kriter geçerliğini belirlemek için kullanılan ölçekler ve kişilerin kendi hayatlarına yönelik yaptıkları birtakım değerlendirmeleri ifade eden değişkenlerden oluşturulan indeksler ile aralarındaki ilişkilerin incelenmesi sonucunda ortaya çıan sonuçlar; Tablo 2 ve Tablo 3 'te verilmiştir.

Tablo 2'de görüldüğü gibi, BFBFÖ-K Toplam Puanı ile Dikkati Düzenleyebilme $(r=.64 ; p<.01)$, Yargllamadan Gözleme ve İzleme $(r=.49 ; p<.01)$, Etkilenmeden Gözleme ve İzleme $(r=.44 ; p<.01), \mathrm{Du}$ yumsal Farkındalık $(r=.43 ; p<.01)$ ve Duygularını Ísimlendirebilme $(r=.61 ; p<.01)$ alt ölçekleri 
Tablo 3. Beş Faktörlü Bilgece Farkındalık Ölçeği - Kısa Formu (BFBFÖ-K), Alt Ölçekleri ve Diğer Bazı Değişkenlerin Ortalama ve Standart Sapma Değerleri ile Değişkenler Arası Korelasyonlar

\begin{tabular}{|c|c|c|c|c|c|c|c|}
\hline Değişkenler & Ort. & S.S. & 6 & 7 & 8 & 9 & 10 \\
\hline $\begin{array}{l}\text { 1. Dikkati } \\
\text { Düzenleyebilme }\end{array}$ & 12,195 & 3,875 & .035 & .110 & $.229 * *$ & $.637 * *$ & $-.389 * *$ \\
\hline $\begin{array}{l}\text { 2. Yargilamadan } \\
\text { Gözleme ve İzleme }\end{array}$ & 12,207 & 3,450 & $.244 * *$ & -.011 & .067 & $.492 * *$ & $-.265 * *$ \\
\hline $\begin{array}{l}\text { 3. Etkilenmeden } \\
\text { Gözleme ve İzleme }\end{array}$ & 12,725 & 3,217 & .006 & -.014 & $.171 * *$ & $.436 * *$ & $-.169 * *$ \\
\hline $\begin{array}{l}\text { 4. Duyumsal Farkındalık } \\
\text { 5. Duygularını }\end{array}$ & 13,780 & 3,216 & -.114 & -.025 & -.093 & $.428 * *$ & -.064 \\
\hline $\begin{array}{l}\text { İsimlendirebilme } \\
\text { 6. Aile İlişkileri }\end{array}$ & 14,383 & 2,936 & .065 & $.144 *$ & $.180 * *$ & $.608 * *$ & $-.211 * *$ \\
\hline $\begin{array}{l}\text { Değerlendirmesi } \\
\text { 7. Hayat }\end{array}$ & 24,297 & 4,375 & - & $.380 * *$ & $.462 * *$ & .085 & $-.297 *$ \\
\hline $\begin{array}{l}\text { Değerlendirmesi } \\
\text { 8. Kendilik }\end{array}$ & 10,660 & 1,875 & & - & $.522 * *$ & .079 & $-.228 * *$ \\
\hline $\begin{array}{l}\text { Değerlendirmesi } \\
\text { 9. BFBFÖ-K Toplam }\end{array}$ & 28,467 & 4,038 & & & - & $.214 * *$ & $-.435 * *$ \\
\hline $\begin{array}{l}\text { Puan } \\
\text { 10. Olumsuz Benlik }\end{array}$ & 65,289 & 8,730 & & & & - & $-.434 * *$ \\
\hline Algis1 & 25,100 & 9,662 & & & & & - \\
\hline
\end{tabular}

$* \mathrm{p}<.05, * * \mathrm{p}<.01$. Not. Ort. ve S. S. kısaltmaları, Ortalama ve Standart Sapma kelimelerini ifade etmektedir.

arasındaki korelasyon değerleri beklenen yöndedir. BFBFÖ-K Toplam Puan ile KSE Toplam Puanı ( $r=$ -.45; $p<.01)$ ve DDGÖ Toplam Puanı $(r=-.59 ; p<$ .01) arasında negatif yönde anlamlı korelasyonlar bulunurken; TBFÖ Toplam Puanı ile arasında pozitif yönde anlamlı bir korelasyon $(r=.23 ; p<.01)$ elde edilmiştir. Benzer şekilde KSE Toplam Puanı ve DDGÖ Toplam Puanı ile Duyumsal Farkındalık alt ölçeği dışındaki tüm alt ölçekler arasındaki korelasyonların negatif yönde anlamlı ilişkiler içinde olduğu, bu korelasyon katsayılarının -.17 ile -.48 ( $<<.01)$ arasında değiştiği görülmüştür. Alt ölçekler ile $T B F O ̈$ Toplam Puanı arasındaki korelasyonlara bakıldığında ise, Dikkati Düzenleyebilme ve Yargllamadan Gözleme ve İzleme alt ölçekleri dışında, diğer üç alt ölçeğin korelasyonlarının .17 ve $.24(\mathrm{p}<.01)$ arasında değişen anlamlı pozitif bir ilişki gösterdiği ortaya koyulmuştur.

BFBFÖ-K Toplam Puanı ve alt ölçekleri ile Demografik Bilgiler ve Kişisel Değerlendirmeler Formu'ndan elde edilen indeks puanları arasındaki ilişkiler Tablo 3'te gösterilmektedir. Tabloda görüldüğü gibi, BFBFÖ-K Toplam Puanı ile Kendilik Değerlendirmesi arasında pozitif yönlü anlamlı bir korelasyon bulunsa da $(r=.21 ; p<.01)$, Aile Illişkileri Değerlendirmesi ve Hayat Değerlendirmesi ile arasında bir ilişki bulunmamıştır. Bunun yanı sıra, Yargılamadan Gözleme ve İzleme alt ölçeği ile Aile İlişkileri Değerlendirmesi $(\mathrm{r}=.24 ; \mathrm{p}<.01)$ arasında pozitif yönde, anlamlı bir korelasyon görülmüştür. Dikkati Düzenleyebilme $(\mathrm{r}=. .23 ; \mathrm{p}<.01)$ ve Etkilenmeden Gözleme ve İzleme $(\mathrm{r}=.17 ; \mathrm{p}<.01)$ alt ölçekleri ile Kendilik Değer- lendirmesi arasında pozitif yönlü ve anlamlı korelasyon değerleri elde edilmiştir. Ek olarak, Duygularını İsimlendirebilme alt ölçeği ile Hayat Değerlendirmesi $(\mathrm{r}=.14 ; \mathrm{p}<.05)$ ve Kendilik Değerlendirmesi $(\mathrm{r}=.18$; $\mathrm{p}<.01)$ indeksleri arasında, pozitif yönlü ve anlamlı korelasyonlar gözlenmiştir.

KSE alt ölçeklerinden Olumsuz Benlik Algısı alt ölçeği ile $B F B F O ̈-K$ Toplam Puan, 4 alt ölçeği $(D u$ yumsal Farkındalık alt ölçeği hariç) ve tüm indeks puanları arasında negatif yönlü ve anlamlı iliş̧kiler elde edilmiştir. $\mathrm{Bu}$ korelasyon değerleri de, Tablo 3 ’te görüldüğü gibi, -.17 ile -.44 arasında değişmektedir.

\section{TARTIŞMA}

Mevcut çalışmada, uyarlanması hedeflenen BFBFÖ$\mathrm{K}$ 'nin, öncelikle faktör yapısı incelenmiştir. Bu inceleme sonucunda, hem Baer ve ark. (2006) tarafindan geliştirilmiş olan orijinal ölçekte, hem bu orijinal ölçeğin Çin ve Hollanda gibi çeşitli ülkelere uyarlanmış formlarında (Deng, Liu, Rodriguez ve Xia, 2011; Veehof, Mooster, Taal, Westerhof ve Bohlmeijer, 2011), hem de Tran ve ark. (2013) tarafindan geliştirilmiş kısa formundaki 5 faktörlü yapının Türkçe formda da korunduğu görülmüştür. Tran ve ark. (2013) tarafindan geliştirilmiş olan orijinal kısa formun Cronbach Alfa katsayıları ile mevcut çalışmadaki alt ölçekler için elde edilenler değerlendirildiklerinde, güvenirlik katsayılarının da benzediği söylenebilir. Orijinal çalışmada tüm alt ölçeklerden elde edilen puanlar ile depresyon ve anksiyete 
puanları arasında negatif yönlü anlamlı korelasyonlar gözlenmiştir (Tran ve ark., 2013). Baer ve ark. (2006) tarafindan geliştirilen ve mevcut çalışmada uyarlanan ölçeğin orijinal uzun formu olan FFMQ'nun Norveç'e uyarlama çalışmasında; farklı ölçek ve alt ölçeklerden elde edilen depresyon puanları ile bilgece farkındalık puanları (toplam puan ve 4 alt ölçekten elde edilenler) arasında negatif yönde anlamlı korelasyonlar elde edilmiştir (Dundas, Vollestad, Binder ve Sivertsen, 2013). Mevcut çalışmada da depresyon, anksiyete, somatizasyon, olumsuz benlik ve hostilite alt ölçeklerinden elde edilen puanların toplamını ifade eden KSE Toplam Puan ile 4 alt ölçek arasında (Dikkati Düzenleyebilme, Yargilamadan Gözleme ve İzleme, Etkilenmeden Gözleme ve İzleme ve Duygularını İsimlendirebilme) negatif yönlü anlamlı korelasyonlar elde edilmiştir. Diğger alt ölçek olan Duyumsal Farkındalık alt ölçeği ile KSE Toplam Puan arasında da negatif yönlü bir korelasyon elde edilmiştir, ancak sonuç anlamlı değildir. Korelasyonun yönünün negatif olması alanyazındaki diğer çalışmalardan elde edilmiş olan bulgularla uyumlu bir yapı sergilediğini düşündürürken (Gillespie, Mitchell, Fisher ve Beech, 2012; Mazaheri, 2015; Özyeşil ve ark., 2011; Tran ve ark., 2013), ilişkinin anlamlı çıkmaması, örneklem sayısına bağlanabilir.

Mevcut çalışmada DDGÖ Toplam Puan aracılı̆̆ ile ölçülen duygu düzenleme güçlügünün, yine söz konusu 4 alt ölçek ile (Dikkati Düzenleyebilme, Yargllamadan Gözleme ve İzleme, Etkilenmeden Gözleme ve İzleme ve Duyguların Ísimlendirebilme) negatif yönde anlamlı korelasyonlara sahip olduğu görülmüştür. Ölçeğin orijinali üzerinde yapılan çalışmada ve diğer başka çalışmalarda da, ölçeğin tüm alt ölçekleri ve çeşitli bilgece farkındalık ölçeklerinin alt ölçekleri ile duygu düzenleme güçlüğü arasında negatif yönlü anlamlı korelasyonlar elde edilmiş̧ir (Çuhadaroğlu ve Aghazade, 2017; Dundas ve ark., 2013; Luberto, Cotton, McLeish, Mingione ve O'Bryan, 2013; Mazaheri, 2015; Roemer ve ark., 2009; Tran ve ark., 2013). Farklı örneklemlerde bilgece farkındalık müdahaleleri gerçekleştirilen çeşitli çalışmalarda da bireylerin duygu düzenleme düzeylerinde artış olduğu belirtilmiştir (Gillespie ve ark., 2012; Siegel, 2007). Bu sonuçlar bir yandan bireylerin bilgece farkındalık puanları arttıkça, stres semptomları ile duygu düzenleme güçlüklerinin azaldığına işaret edebileceği gibi; kişinin stres semptomları ve duygu düzenleme güçlükleri arttıkça, bilgece farkındalık özelliklerinin azaldığına da işaret edebilir.

Mevcut çalışmada, BFBFÖ-K Toplam Puan, 3 alt ölçeği ve kriter geçerliğini ölçmek için kullanılan TBFÖ Toplam Puan (Hisli Şahin ve Yeniçeri, 2015) arasında pozitif yönlü anlamlı korelasyonlar elde edilmiştir. Benzer şekilde, Türkçeye Bilinçli Farkındalık Ölçeği adıyla uyarlanmış olan MAAS'ın (Özyeşil ve ark., 2011) İspanyolca uyarlama çalışmasın- da, MAAS toplam puanı ile çalışmada kullanılan bir diğer ölçek olan FFMQ'nun 4 alt ölçeği arasında pozitif yönde anlamlı korelasyonlar elde edilmiştir (Soler ve ark., 2012). Bu sonuç da, mevcut çalışma ile söz konusu İspanyolca uyarlama çalışmasının birer bilgece farkındalık ölçeği uyarlama çalışması olması açısından göz önünde bulundurulduğunda, BFBFÖ-K'nin geçerliğine yönelik bir bulgu olarak değerlendirilebilir.

Çalışmamızda elde edilen bulgular, BFBFÖ$\mathrm{K}$ 'den elde edilen toplam puan ve üç alt ölçekten (Etkilenmeden Gözleme ve İzleme, Duyguların Ísimlendirebilme ve Dikkati Düzenleyebilme) elde edilen puanların, Demografik Bilgi ve Kişisel Değerlendirmeler Formu'ndaki bazı maddeler üzerinden elde edilen Kendilik Değerlendirmesi, Aile İlişkileri Degerlendirmesi ve Hayat Değerlendirmesi puanlarıla gösterdikleri beklenen yöndeki ilişkiler de, ölçeğin geçerliğine yönelik ek bazı bulgular olarak değerlendirilebilir. Örneğin; ölçeğin toplam puanı, Dikkati Düzenleyebilme, Etkilenmeden Gözleme ve İzleme ve Duygularını İsimlendirebilme alt ölçekleri ile Kendilik Değerlendirmesi arasında gözlenen anlamlı ve pozitif yöndeki korelasyonlar (Bkz. Tablo 3), ilgili yazında da gözlenmektedir. Kendilik Değerlendirmesi indeks puanını oluşturan maddelerin içeriğine bakıldığında, söz konusu maddelerin kişinin kendisine yönelik algılarını yansıttı̆̆ı düşünülebilir. Pepping, O'Donovan ve Davis (2013) özsaygiyı "bir bireyin kendi değerine yönelik yaptığ 1 değerlendirme" şeklinde tanımlamaktadır. Yaptıkları çalışmada FFMQ'nun dört alt ölçeği (Etkilenmeme, İsimlendirebilme, Yargılamama ve Farkındalı) ile özsaygı arasında pozitif yönlü anlamlı ilişkiler saptamışlardır. Mevcut çalışmadan elde edilen Kendilik Değerlendirmesi ve ölçek puanları arasındaki pozitif korelasyonun Pepping ve arkadaşlarının (2013) çalışma bulguları ile tutarlı sonuçlar ortaya koyduğu düşünülmektedir. Kendilik Değerlendirmesi indeks puanının, KSE alt ölçeklerinden olan Olumsuz Benlik Algisı alt ölçeği ile gösterdiği yüksek düzeydeki negatif ve anlamlı korelasyonunun da (Bkz. Tablo 3) yukarıdaki yorumu destekleyici bir bulgu olduğu söylenebilir.

Duygularını İsimlendirebilme alt ölçeği ile Hayat Değerlendirmesi indeks puanı arasında da pozitif yönde anlamlı bir ilişki elde edilmiştir. Hayat Değerlendirmesi indeks puanını oluşturan maddelerin içeriği incelendiğinde de, bu indeks puanının yaşam doyumuna benzer bir boyutu değerlendirmeye çalıştığ düşünülebilir. Çeşitli çalışmalarda, bilgece farkındalığın yaşam doyumu, ilişki doyumu, empati gelişimi ve etkili iletişism ile pozitif yönde ilişkili olduğuna dair bulgular mevcuttur (Gambrel ve Keeling, 2010; Pepping ve ark., 2013; Stolarski, Vowinckel, Jankowski ve Zajenkowski, 2016).

Yargılamadan Gözleme ve İzleme alt ölçeği ile $A i$ le İlişkileri Değerlendirmesi indeks puanından elde 
edilen puanlar arasında güçlü bir ilişki gözlenmiştir. Mevcut çalışmada Aile İlişkileri Değerlendirmesi indeks puanı, kişinin içinde büyümüş olduğu ailesine yönelik değerlendirmeleri içeren maddelerden oluşturulmuştur. Bir anlamda kişinin bağlanma örüntüsüne yönelik bilgiler sağlaması amaçlanmıştır. Bu indeks puanı ile BFBFÖ-K'deki yukarıda söz edilen alt ölçek arasında elde edilmiş olan güçlü ilişkinin de yine alanyazındaki bazı bulgularla desteklendiği ileri sürülebilir (Pickard, Caputi ve Greneyer, 2016). Bilgece farkındalığın, aynı zamanda, ebeveyn ile çocuk arasında adaptif olmayan örüntülerin kırılmasına ve ebeveynlerin daha uyumlu iletişim kurmasına da yardımcı olduğu ileri sürülmektedir (Siegel, 2007). Mevcut çalışmada, Aile İlişkileri Değerlendirmesi indeks puanı ile yansıyabileceği düşünülen, kişinin içinde büyümüş olduğu aile ilişkilerine yönelik geriye dönük yapılan değerlendirmesi ile Yargılamadan Gözleme ve İzleme alt ölçeği arasında çıkan anlamlı pozitif ilişki, bu bağlamda da yorumlanabilir.

Bütün bu bulguların ışığında, BFBFÖ-K'nin psikometrik özelliklerinin orijinal ölçek ile tutarlı olduğu ve geçerlik ölçümleriyle olan ilişkilerin de beklenen yönde olduğu dikkate alınacak olursa, ölçeğin bu kısa formunun Türkiye'de bilgece farkındalığı ölçmek

\section{KAYNAKLAR}

Antoni, M. H., Cruess, D. G., Cruess, S., Lutgendorf, S., Kumar, M., Ironson, G., ...Schneiderman, N. (2000). Cognitive-behavioral stress management intervention effects on anxiety, 24-hr urinary norepinephrine output, and T-cytotoxic/suppressor cells over time among symptomatic HIV-infected gay men. Journal of Consulting and Clinical Psychology, 68(1), 31-45.

Baer, R. A., Smith, G. T. ve Allen, K. B. (2004). Assessment of mindfulness by self-report: The Kentucky Inventory of Mindfulness Skills. Assessment, 11, 191206.

Baer, R. A., Smith, G. T., Hopkins, J., Krietemeyer, J. ve Toney, L. (2006). Using self-report assessment methods to explore facets of mindfulness. Assessment, 13(1), 27-45.

Bergomi, C., Tschacher, W. ve Kupper, Z. (2013). The assessment of mindfulness with self-report measures: Existing scales and open issues. Mindfulness, 4, 191202.

Bourne, K., Berry, K. ve Jones, L. (2013). The relationships between psychological mindedness, parental bonding and adult attachment. Psychology and Psychotherapy: Theory, Research and Practice, 1-11.

Brown, K. W. ve Ryan, R. M. (2003). The benefits of being present: Mindfulness and its role in psychological well-being. Journal of Personality and Social Psychology, 84, 822-848.

Brown, K. W., Weinstein, N ve Creswell, J. D. (2012). Trait mindfulness modulates neuroendocrine and affective responses to social evaluative threat. Psychoneuroendocrinology, 37, 2037-2041. amacıyla güvenli bir şekilde kullanılabileceği söylenebilir. Ancak her çalışmada bazı sınırlılıklar olabildiği gibi, bu çalışmada da iki önemli sınırlılık olduğundan söz edilebilir. Bunlardan ilki, örneklemin sınırlılığıyla ilişkilidir. Mevcut çalışmanın örnekleminde yaş dilimleri ve eğitim düzeyleri dengeli bir şekilde dağılmamıştır. O nedenle ölçeğin bu çalışma ile uyarlanmış olan Türkçe formunun daha temsili ve daha büyük örneklemlerle, aynı zamanda klinik örneklemlerle de çalışılmasında yarar vardır. İkinci sınırlılık ise, ölçeğin bir öz-bildirim ölçeği olmasıdır. $\mathrm{Bu}$ nedenle bundan sonra yapılacak çalışmalarda ölçeğin geçerliğinin essansiyel yüksek tansiyon gibi fizyolojik ölçümlerle ya da dikkat, konsantrasyon ölçümlerinde yardımcı olan bazı nöropsikolojik testlerle incelenmesinin yararlı olacağı düşünülmektedir. Ayrıca ölçeğin prefrontal işlevler ile yönetici işlevleri ölçen araçlarla birlikte değerlendirilmesinin ve bağlanma örüntüleri ile ilişkisinin incelenmesinin de önerilebilecek yeni araştırma soruları olabileceği düşünülmektedir. Aynı şekilde yapılabilecek çeşitli psikoterapi müdahalelerinin öncesinde ve sonrasinda açı̆̆a çıkması muhtemel olumlu yöndeki değişimler açısından da değerlendirilmesi, ölçeğin ayırıcı geçerliğine ilişkin ek katkılar sağlayabilir.

Brown-Ianuzzi, J. L., Adair, K. C., Payne, B. K., Richman, L. S. ve Fredrickson, B. L. (2014). Discrimination hurts, but mindfulness may help: Trait mindfulness moderates the relationship between perceived discrimination and depressive symptoms. Personality and Individual Differences, 56, 201-205.

Cardaciotto, L., Herbert, J. D., Forman, E. M., Moitra, E. ve Farrow, V. (2008). The Assessment of presentmoment awareness and acceptance: The Philadelphia Mindfulness Scale. Assessment, 15(2), 204-223.

Carlson, L. E., Speca, M., Faris, P. ve Patel, K. D. (2007). One year pre-post intervention follow-up of psychological, immune, endocrine and blood pressure outcomes of mindfulness-based stress reduction (MBSR) in breast and prostate cancer outpatients. Brain, Behavior and Immunity, 21, 1038-1049.

Chadwick, P., Hember, M., Symes, J., Peters, E., Kuipers, E. ve Dagnan, D. (2008). Responding mindfully to unpleasant thoughts and images: Reliability and validity of the Southampton Mindfulness Questionnaire (SMQ). British Journal of Clinical Psychology, 47, 451-455.

Cullen, M. (2011). Mindfulness-based interventions: an emerging phenomenon. Mindfulness, 2, 186-193.

Çuhadaroğlu, F. Ç. ve Aghazade, S. (2017). Evaluation of emotion regulation and mindfulness in adolescents with and without identity confusion. Journal of the American Academy of Child \& Adolescent Psychiatry, 56(10), 156.

Davidson, R. J., Kabat-Zinn, J., Schumacher, J., Rosenkranz, M., Muller, D., Santorelli, S. F., ...Sheridan, J. F. (2003). Alterations in brain and immune function produced by mindfulness meditation. Psychosomatic Medicine, 65, 564-570. 
Deng, Y., Liu, X., Rodriguez, M. A. ve Xia, C. (2011). The Five Facet Mindfulness Questionnaire: Psychometric properties of the Chinese version. Mindfulness, 2(2), 123-128.

Dundas, I., Vollestad, J., Binder, P. ve Sivertsen, B. (2013). The Five Factor Mindfulness Questionnaire in Norway. Scandinavian Journal of Psychology, 54, 250260.

Feldman, G., Hayes, A., Kumar, S., Greeson, J. ve Laurenceau, J. P. (2007). Mindfulness and emotion regulation: The development and initial validation of the Cognitive and Affective Mindfulness Scale-Revised (CAMS-R). Journal of Psychopathology and Behavioral Assessment, 29, 177-190.

Frewen, P. A., Dozois, D. J. A., Neufeld, R. W. J, Lane, R. D., Densmore, M., Stevens, T. K. ve Lanius, R. A. (2010). Individual differences in trait mindfulness predict dorsomedial prefrontal and amygdala response during emotional imagery: An fMRI study. Personality and Individual Differences, 49(5), 479-484.

Gambrel, L. E. ve Keeling, M. L. (2010). Relational aspects of mindfulness: Implications for the practice of marriage and family therapy. Contemporary Family Therapy, 32, 412-426.

Gillespie, S. M., Mitchell, I. J., Fisher, D. ve Beech, A. R. (2012). Treating disturbed emotional regulation in sexual offenders: The potential applications of mindful self-regulation and controlled breathing techniques. Aggression and Violent Behavior, 17, 333-343.

Gratz, K. L. ve Roemer, E. (2004). Multidimensional assessment of emotion regulation and dysregulation: Development, factor structure, and initial validation of the difficulties in Emotion Regulation Scale. Journal of Psychopathology and Behavioral Assessment, 26(1), 41-54.

Hill, C. L. M. ve Updegraff, J. A. (2012). Mindfulness and its relationship to emotional regulation. Emotion, 12(1), 81-90.

Hisli Şahin, N., Durak Batıün, A. ve Uğurtaş, S. (2002). Kısa Semptom Envanteri (KSE): Ergenler için kullanımının geçerlik, güvenilirlik ve faktör yapısı. Türk Psikiyatri Dergisi, 13(2), 125-135.

Hisli Şahin, N. ve Yeniçeri, Z. (2015). "Farkındalık" üzerine üç araç: Psikolojik Farkındalık, Bütünleyici Kendilik Farkındalığı ve Toronto Bilgece Farkındalık Ölçekleri. Türk Psikoloji Dergisi, 30(76), 48-64.

Hölzel, B. K., Carmody, J., Vangel, M., Congleton, C., Yerramsetti, S. M., Gard, T. ve Lazar, S. W. (2011). Mindfulness practice leads to increases in regional brain gray matter density. Psychiatry Research, 191, 36-43.

Hülsheger, U. R., Alberts, H. J. E. M., Feinholdt, A. ve Lang, J. W. B. (2012). Benefits of mindfulness at work: The role of mindfulness in emotion regulation, emotional exhaustion, and job satisfaction. Journal of Applied Psychology. Advance online publication.

Jimenez, S. S., Niles, B. L. ve Park, C. L. (2010). A mindfulness model of affect regulation and depressive symptoms: Positive emotions, mood regulation expectancies, and self-acceptance as regulatory mechanisms. Personality and Individual Differences, 49, 645-650.

Jordan, C. H., Wang, W. ve Donatoni, L. R. (2014). Mindful eating: Trait and state mindfulness predict healthier eating behavior. Personality and Individual Differences, 68(1), 107-111.

Kabat-Zinn, J. (1994). Wherever you go, there you are: Mindfulness meditation in everyday life. New York, NY: Hyperion.

Kabat-Zinn, J., Wheeler, E., Light, T. Skillings, A., Scharf, M. J., Cropley, T. G., ...Bernhard, J. D. (1998). Influence of a Mindfulness Meditation-Based Stress Reduction Intervention on rates of skin clearing in patients with moderate to severe psoriasis undergoing phototherapy (UVB) and photochemotherapy (PUVA). Psychosomatic Medicine, 60, 625-632.

Karacaoğlan, B. ve Hisli Şahin, N. (2016). Bilgece farkındalık ve duygu düzenleme becerisinin iş tatminine etkisi. Işsletme Araştırmaları Dergisi, 8(4), 421-444.

Kınay, F. (2013). Beş Boyutlu Bilinçli Farkındalık Ölçeği'ni Türkçe'ye Uyarlama, Geçerlik ve Güvenirlik Çalışması (Yayınlanmamış yüksek lisans tezi). İstanbul Bilim Üniversitesi, İstanbul.

Kiken, L. G., Garland, E. L., Bluth, K., Palsson, O. S. ve Gaylord, S. A. (2015). From a state to a trait: Trajectories of state mindfulness in meditation during intervention predict changes in trait mindfulness. Personality and Individual Differences, 81, 41-46

Langer, E. J. (1989). Mindfulness. Cambridge, MA: Da Capo Press.

Langer, E. J., ve Moldoveanu, M. (2000). The construct of mindfulness. Journal of Social Issues, 56, 1-9.

Lau, M. A., Bishop, S. R., Segal, Z. V., Buis, T., Anderson, N. D., Carlson, L., ....Devins, G. (2006). The Toronto Mindfulness Scale: Development and validation. Journal of Clinical Psychology, 62(12), 1445-1467.

Levy, B., ve Langer, E. J. (1999). Aging. Encyclopedia of creativity içinde (Vol. 1, pp. 45-52). San Diego, CA: Academic Press.

Luberto, C. M., Cotton, S., McLeish, A. C., Mingione, C. J. ve O'Bryan, E. M. (2013). Mindfulness skills and emotion regulation: the mediating role of coping selfefficacy. Mindfulness, 5(4), 1-7.

Lutz, A., Greischar, L. L., Rawlings, N. B., Ricard, M. ve Davidson, R. J. (2004). Long-term meditators selfinduce high-amplitude gamma synchrony during mental practice. Proceedings of the National Academy of Sciences of the United States of America, 101(46), 16369-16373.

Lyvers, M., Makin, C., Toms, E., Thorberg, F. A. ve Samios, C. (2014). Trait mindfulness in relation to emotional self-regulation and executive function. Mindfulness, 5, 619-625.

Mazaheri, M. (2015). Difficulties in emotion regulation and mindfulness in psychological and somatic symptoms of functional gastrointestinal disorders. Iranian Journal of Psychiatry and Behavioral Sciences, 9(4), 17.

Murakami, H., Nakao, T., Matsunaga, M., Kasuya, Y., Shinoda, J., Yamada, J. ve Ohira, H. (2012). The structure of mindful brain. Plos One, 7(9), 1-4.

Özyeşil, Z., Arslan, C., Kesici, Ş. ve Deniz, M. E. (2011). Bilinçli Farkındalık Ölçeği'ni Türkçe'ye Uyarlama Çalışması. Eğitim ve Bilim, 36(160), 224-235.

Paul, N. A., Stanton, S. J., Greeson, J. M., Smoski, M. J. ve Wang, L. (2013). Psychological and neural 
mechanisms of trait mindfulness in reducing depression vulnerability. SCAN, 8, 56-64.

Pepping, C. A., O’Donovan, A. ve Davis, P. J. (2013). The positive effects of mindfulness on self-esteem. The Journal of Positive Psychology, 8(5), 376-386.

Pepping, C. A., O'Donovan, A. ve Davis, P. J. (2014). The differential relationship between mindfulness and attachment in experienced and inexperienced meditators. Mindfulness, 5, 392-399.

Pickard, J. A., Caputi, P. ve Greneyer, F. S. (2016). Mindfulness and emotional regulation as sequential mediators in the relationship between attachment security and depression. Personality and Individual Differences, 99, 179-183.

Pirson, M. A., Langer, E., Bodner, T. E. ve Zilcha-Mano, S. (2012). The development and validation of the Langer Mindfulness Scale - Enabling a socio-cognitive perspective of mindfulness in organizational contexts. Fordham University Schools of Business Research Paper. 8 Ekim 2012,https://ssrn.com/abstract=2158921

Potts, S. (2015). The Relationship of Trait Mindfulness and Positive Mental and Physical Health Among College Students (Yayınlanmamış yüksek lisans tezi). Utah State University, Utah.

Proulx, K. (2008). Experiences of women with bulimia nervosa in a mindfulness-based eating disorder treatment group. Eating Disorders, 16(1), 52-72.

Roemer, L., Lee, J. K., Salters-Pedneault, K., Erisman, S. M., Orsillo, S. M. ve Mennin, D. S. (2009). Mindfulness and emotion regulation difficulties in generalized anxiety disorder: Preliminary evidence for independent and overlapping contributions. Behavior Therapy, 40(2), 142-154.

Ruganc1, N. R. ve Gençöz, T. (2010). Psychometric properties of a Turkish version of the difficulties in emotion regulation scale. Journal of Clinical Psychology, 66(4), 442-455.

Siegel, D. J. (2007). The mindful brain. New York: W. W. Norton.

Soler, J., Tejedor, R., Feliu-Soler, A., Pascual, J. C., Cebolla, A., Soriano, J., ....Perez, V. (2012). Psychometric proprieties of Spanish version of Mindful Attention Awareness Scale (MAAS). Actas Espanolas De Psiquiatria, 40(1), 19-26.

Stolarski, M., Vowinckel, J., Jankowski, K. S. ve Zajenkowski, M. (2016). Mind the balance, be contented: Balanced time perspective mediates the relationship between mindfulness and life satisfaction. Personality and Individual Differences, 93, 27-31.

Teper, R., Segal, Z. V. ve Inzlicht, M. (2013). Inside the mindful mind: How mindfulness enhances emotion regulation through improvements in executive control. Current Directions in Psychological Science, 22(6), 449-454.

Tran, U. S., Glück, T. M. ve Nader, I. W. (2013). Investigating the Five Facet Mindfulness Questionnaire (FFMQ): Construction of a short form and evidence of a two-factor higher order structure of mindfulness. Journal of Clinical Psychology, 69(9), 951-965.

Veehof, M. M., Klooster, P. M., Taal, E., Westerhof, G. J. ve Bohlmeijer, E. T. (2011). Psychometric properties of Dutch Five Facet Mindfulness Questionnaire
(FFMQ) in patients with fibromyalgia. Clinical Rheumatology, 30(8), 1045-1054.

Young, S. N. (2007). How to increase serotonin in the human brain without drugs. Journal of Psychiatry and Neuroscience, 32(6), 394-399.

Young, S. N. (2011). Biologic effects of mindfulness meditation: growing insights into neurobiology aspects of the prevention of depression. Journal of Psychiatry \& Neuroscience, 36(2), 75-77.

Walach, H., Buchheld, N., Buttenmüller, V., Kleinknecht, N. ve Schmidt, S. (2006). Measuring mindfulness - the Freiburg Mindfulness Investor (FMI). Personality and Individual Differences, 40, 1543-1555.

Walsh, J. J., Balint, M. G., Smolira SJ, D. R., Fredericksen, L. K. ve Madsen, S. (2009). Predicting individual differences in mindfulness: The role of trait anxiety, attachment anxiety and attentional control. Personality and Individual Differences, 46, 94-99. 